Check for updates

Cite this: RSC Adv., 2017, 7, 45085

Received 8th July 2017

Accepted 27th August 2017

DOI: $10.1039 / \mathrm{c} 7 \mathrm{ra07530h}$

rsc.li/rsc-advances

\title{
One-pot fabrication of ferric ferrocyanide functionalized graphene hydrogel for cesium removal in aqueous solution
}

\author{
Yan-Rong He, Yang Yang, Zhao-Ya Huang, Wei-Juan Wang, Xiao-Long Li, \\ Peng-Hao Zhang, Zhao-Yi Tan* and Dong Zhang (D)*
}

\begin{abstract}
The rapid development of the nuclear industry brings benefits for global economic development and solves the energy crisis. However, nuclear industrial activities produce a large amount of radioactive wastewater, which poses serious threats to environmental safety and human health, and ${ }^{137} \mathrm{Cs}$ is considered one of the most abundant radionuclides in radioactive wastewater. In this study, we fabricated a new type of ferric ferrocyanide (Prussian blue, PB) functionalized graphene hydrogel $(\mathrm{PB} / \mathrm{rGOH})$ for $\mathrm{Cs}(\mathrm{I})$ removal. The as-prepared $\mathrm{PB} / \mathrm{rGOH}$ shows a three dimensional network with $\mathrm{PB}$ nanoparticles uniformly distributed on the surface of the $\mathrm{rGO}$ sheets. The $\mathrm{PB} / \mathrm{rGOH}$ could be readily separated from aqueous solution. Moreover, the volume of the composite could shrink to a small stiff bulk material, further reducing the volume of the waste. Kinetics experiments showed that $\mathrm{Cs}(\mathrm{I})$ adsorption on $\mathrm{PB} / \mathrm{rGOH}$ fitted well with pseudo-second-order kinetic model, and the equilibrium data agreed well with the Langmuir model. As calculated from the Langmuir model, the maximum adsorption capacity at $\mathrm{pH} 5.0$ is $58.82 \mathrm{mg} \mathrm{g}^{-1}$. The increase of $\mathrm{pH}$ from 3 to 7 could enhance the adsorption capacity, however, further increasing the $\mathrm{pH}$ value resulted in serious decomposition of $\mathrm{PB}$ nanoparticles. In conclusion, the $\mathrm{PB} / \mathrm{rGOH}$ prepared in our work showed good performance on removal of $\mathrm{Cs}(1)$ in aqueous solution, and has a good application prospect in radioactive waste water treatment.
\end{abstract}

\section{Introduction}

Currently, global climate change and fossil fuel depletion have impelled more and more countries to develop alternative clean energy. Nuclear power, which supplied about $4.8 \%$ of the world's energy in 2014 , is widely considered as a sustainable solution to the global energy crisis. ${ }^{\mathbf{1 , 2}}$ However, nuclear industrial activities pose many threats to the environment and human health due to the release of large amounts of radioactive wastewater, including radioactive waste leaking from tanks and released during nuclear power plant accidents. ${ }^{3,4}$ For example, in the Fukushima accident on March 11, 2011, huge amounts of radionuclides such as ${ }^{134} \mathrm{Cs},{ }^{137} \mathrm{Cs},{ }^{131} \mathrm{I}$, and ${ }^{90} \mathrm{Sr}$ were released into the water, air, and land, and the control and removal of radioactive wastes from polluted water and soil have been gaining interest world wide.

According to previous researches, the direct release of ${ }^{137} \mathrm{Cs}$ into the environment is considered as one the most abundant radionuclide. ${ }^{5}$ Being one of the most hazardous contaminants, ${ }^{137} \mathrm{Cs}$ has a long half-life of 30.1 years and emits beta-particles and strong gamma rays. ${ }^{6}$ In addition, based on its chemical similarity to potassium, Cs(I) has high solubility and could

Institute of Nuclear Physics and Chemistry, China Academy of Engineering Physics, Mianyang,621000,China.E-mail:tanzhaoyi@caep.cn; zdo823@caep.cn favorably migrate through groundwater to the food chain. ${ }^{7}$ Thus, it is necessary to develop an effective extraction process to remove the radioactive $\mathrm{Cs}(\mathrm{I})$ from wastewater. Ferric ferrocyanide (Prussian blue, $\mathrm{PB}$ ) and its analogous hexacyanoferrate compounds are well-known adsorbents for the selective removal of cesium ions owing to its radiation stability, high adsorption capacity, low-cost and biocompatibility. PB has been effectively used to treat Cs(I) exposure after the Chernobyl nuclear reactor disaster and the Goiania accident. ${ }^{8,9}$ However, to maintain a high adsorption capacity, PB is usually in the form of a very fine powder, which makes it difficult to be separated from aqueous solutions by filtration or centrifugation after Cs(I) sorption. In addition, these small particles cannot be directly used in fixed-bed columns due to the pressure and clogging. To address these problems, numerous studies have been dedicated to the immobilization of $\mathrm{PB}$ nanoparticles in porous materials or at the surface of structural materials. ${ }^{7,8,10-15}$ Fox example, Jang et al. bound $\mathrm{PB}$ nanoparticles to the core of magnetite $\left(\mathrm{Fe}_{3} \mathrm{O}_{4}\right)$ nanoparticles, achieving highly efficient and rapid separation of Cs(I) from aqueous solution. ${ }^{13}$

In recent years, graphene hydrogels and aerogels have received more and more attentions because of their large surface area, high conductivity, excellent mechanical flexibility and chemical stability. ${ }^{\mathbf{1 6 , 1 7}}$ The porous network and large surface area make graphene hydrogels/aerogels effective 


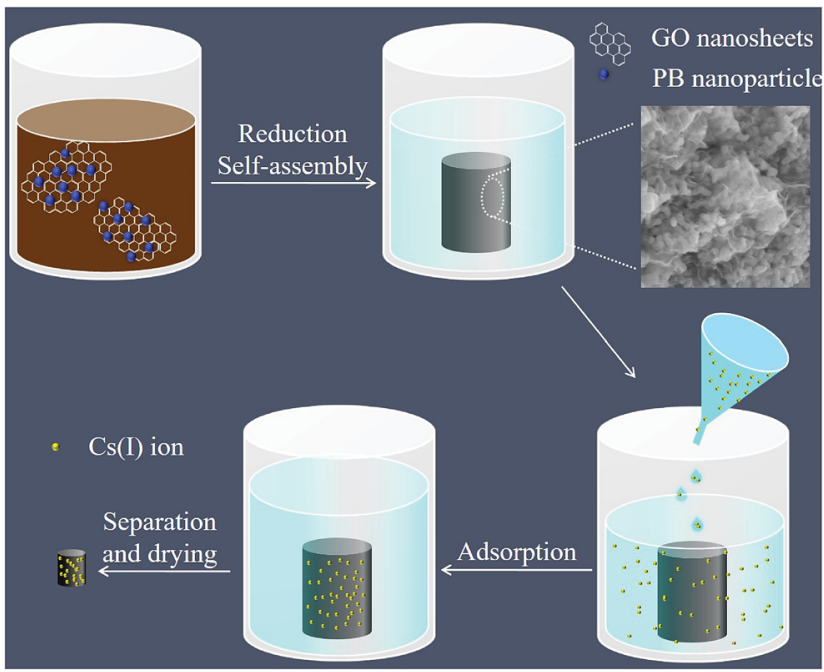

Fig. 1 Schematic of approach for $\mathrm{PB} / \mathrm{rGOH}$ and $\mathrm{Cs}(1)$ removal.

support materials for nanoparticle dispersion. ${ }^{18-21}$ Adhikari et al. prepared metal nanoparticles containing graphene hybrid hydrogel as a potential catalyst for the reduction of aromatic nitro to amino group. ${ }^{22}$ Zhang et al. fabricated graphene-based nanohybrid material to support Pd nanoparticles and obtained uniformly distributed Pd nanoparticles on the surface of graphene sheets. ${ }^{23}$ In our previous work, we found that after air dried, graphene hydrogel could shrink to form graphite-like bulk materials, accompanying with a significant volume reduction. Such a volume reduction is beneficial to waste minimization. Therefore, graphene hydrogel could be a promising support material for utilizing PB nanoparticles for $\mathrm{Cs}(\mathrm{I})$ removal in radioactive wastewater.

Based on the above, in this study, we fabricated PB nanoparticles functionalized graphene hydrogel $(\mathrm{PB} / \mathrm{rGOH})$ and developed a new approach to remove $\operatorname{Cs}(\mathrm{I})$ from aqueous solution as shown in Fig. 1. The $\mathrm{PB} / \mathrm{rGOH}$ was fabricated by reducing graphene oxide (GO) using ascorbic acid in the presence of PB nanoparticles. The physical and chemical properties of the prepared materials were characterized, Cs(I) adsorption performance of $\mathrm{PB} / \mathrm{rGOH}$ were determined, and the application prospect of the material in radioactive wastewater treatment was estimated.

\section{Experimental}

\section{Fabrication of $\mathrm{PB} / \mathrm{rGOH}$}

GO was prepared by oxidizing nature graphite powder (325 mesh) using a modified method as described previously. ${ }^{24}$ In our work, aqueous suspensions of GO with a concentrations of $1.5 \mathrm{mg} \mathrm{mL} \mathrm{m}^{-1}$ was used. PB nanoparticles, purchased from Aladdin Industrial Co., China, were ultrasonically dispersed in deionized water for about 24 hours prior to use, with a concentration of $15 \mathrm{mg} \mathrm{mL}^{-1}$. To prepare $\mathrm{PB} / \mathrm{rGOH}: 4 \mathrm{~mL}$ of $\mathrm{GO}$ suspensions, $0.4 \mathrm{~mL}$ of $\mathrm{PB}$ suspension, $1 \mathrm{~mL}$ of ascorbic acid $\left(42 \mathrm{~g} \mathrm{~L}^{-1}\right)$, and $1.6 \mathrm{~mL}$ of distilled water were mixed into a glass bottle with a volume of $10 \mathrm{~mL}$, then the mixed suspension was heated at $60^{\circ} \mathrm{C}$ for $5 \mathrm{~h}$. To obtain $\mathrm{PB} / \mathrm{rGOH}$ with different $\mathrm{PB} / \mathrm{GO}$ $(\mathrm{w} / \mathrm{w})$ ratios, the conditions was maintained as the above, except that the volumes of $\mathrm{PB}$ suspension was $0,0.2,0.4,0.8,1.2$, $2.0 \mathrm{~mL}$, respectively. Afterwards, the total volume of the mixture were supplemented to $7 \mathrm{~mL}$ with deionized water. The as-prepared materials were dialyzed against deionized water for 2 days to remove residual micromolecules prior to use. As control subject, $\mathrm{rGOH}$ was fabricated by the same step except that deionized water was used to replace the PB suspension.

\section{Characterization of $\mathrm{PB} / \mathrm{rGOH}$}

Scanning electron microscope (SEM, Ultra 55, Carl Zeiss Ltd., Germany) was used to characterize the morphology of the $\mathrm{PB} / \mathrm{rGOH}$. Transmission electron microscopy (TEM) images of the $\mathrm{PB} / \mathrm{rGOH}$ were obtained on a Libra 200FE instrument (Carl Zeiss Ltd., Germany). X-ray photoelectron spectroscopy (XPS) tests were conducted using an ESCALAB 250 instrument (Thermo-VG Scientific Inc., USA). The XPS data were analyzed with curvefitting software (XPSPEAK v4.1). X-ray diffraction (XRD) tests were conducted on an Empyrean instrument (PANalytical, Co., The Netherlands). Raman spectra were taken with aninVia confocal Raman Microscope (Renishaw Co., UK) with a $532 \mathrm{~nm}$ laser excitation. Nitrogen adsorption/desorption isotherms were obtained on a JW-BK200C (JWGB Sci. \&Tech. Co., China), and before the measurement, the solid was completely dehydrated by heating at $200{ }^{\circ} \mathrm{C}$ for $6 \mathrm{~h}$ under vacuum. The samples used in SEM, XPS, XRD, Raman, and nitrogen adsorption/desorption isotherm analyses were freeze-dried.

\section{$\operatorname{Cs}(\mathrm{I})$ adsorption tests}

The adsorption experiment was conducted for the $\mathrm{PB} / \mathrm{rGOH}$ by immersing it in $\mathrm{Cs}(\mathrm{I})$ solution with varied initial concentration of $\mathrm{Cs}(\mathrm{I})$. Except for specially stated, the dried weight of $\mathrm{PB} / \mathrm{rGOH}$ was $9 \mathrm{mg}$, and the volume of $\mathrm{Cs}(\mathrm{I})$ solution was $15 \mathrm{~mL}$. The solution $\mathrm{pH}$ was adjusted using $\mathrm{HCl}(5 \mathrm{M}, 0.5 \mathrm{M}, 0.05 \mathrm{M}$, and $0.005 \mathrm{M})$ or $\mathrm{NaOH}(5 \mathrm{M}, 0.5 \mathrm{M}, 0.05 \mathrm{M}$, and $0.005 \mathrm{M})$, and all the experiments were conducted at $25{ }^{\circ} \mathrm{C}$ with a shaking speed of $125 \mathrm{rpm}$. At the given time, the $\operatorname{Cs}(\mathrm{I})$ concentration in the supernatant was detected by inductively coupled plasma-atomic absorption spectrometry (ICP-AAS, ZEENT 700P, Analytikjena Co., Germany). The adsorption amounts of $\operatorname{Cs}(\mathrm{I})$ at equilibrium $\left(q_{\mathrm{e}}\right)$ and removal efficiency (RE) of Cs(I) were calculated according to eqn (1) and (2), respectively:

$$
\begin{gathered}
q_{\mathrm{e}}=\left(C_{0}-C_{\mathrm{e}}\right) \frac{V}{m} \\
\operatorname{RE}(\%)=\frac{C_{0}-C_{\mathrm{e}}}{C_{0}} \times 100
\end{gathered}
$$

where $C_{0}$ and $C_{\mathrm{e}}\left(\mathrm{mg} \mathrm{L}^{-1}\right)$ are the initial and residual concentration of $\mathrm{Cs}(\mathrm{I})$ in solution, respectively. $V(\mathrm{~L})$ is the volume of the aqueous solution, and $m(\mathrm{~g})$ is the adsorbent weight.

\section{Results and discussion}

\section{Morphology}

In the present study, we fabricated $\mathrm{PB} / \mathrm{rGOH}$ by reducing $\mathrm{GO}$ using ascorbic acid in the presence of PB nanoparticles. Fig. 2a 
shows the changes of the reaction system versus the reaction time. As the reduction time increased, the volume of mixed GO and PB nanoparticles shrunk greatly compared to its initial size and the blue-black suspension turned black, indicating that along with the reducing of GO, PB nanoparticles was embedded in the $\mathrm{rGOH}$, and the self-assembled $\mathrm{PB} / \mathrm{rGOH}$ formed. To examine the stability of the $\mathrm{PB} / \mathrm{rGOH}$, the hydrogel was shaken at $125 \mathrm{rpm}$ for $72 \mathrm{~h}$, and it still maintain an intact structure even after $72 \mathrm{~h}$ of shaking as shown in Fig. $2 \mathrm{~b}$. The SEM images of the freeze-dried rGO gel (Fig. $2 \mathrm{c}$ and d) and $\mathrm{PB} / \mathrm{rGO}$ gel (Fig. 2e and f) show that rGO sheets display a smooth surface, while $\mathrm{PB} / \mathrm{rGO}$ shows a rugged surface, confirming the adhering of $\mathrm{PB}$ nanoparticles on the surface of the rGO sheets. Both materials showed a well-defined and interconnected 3D porous network, and the pore sizes of the network were in micro scale. Taking advantage of their welldefined $3 \mathrm{D}$ porous structure, the $\mathrm{rGOH}$ and the $\mathrm{PB} / \mathrm{rGOH}$ displayed a high water content of $99.67 \%$ and $98.54 \%$, respectively. Such an interconnected 3D porous network could allow aqueous solution to flow through, ensuring effective mass transfer in the treatment of wastewater.
TEM images show that after reduction, rGO sheets stacked and formed the pore walls of the hydrogel (Fig. 3a, c and d). Meanwhile, different from the agglomerated state (Fig. 3b), PB nanoparticles were uniformly dispersed in the lamellar spacing of the rGO sheets (Fig. 3d). This could be possibly attributed to the improvement of the stability of PB nanoparticles due to the presence of rGO sheets in aqueous solution, and would be beneficial to the interaction between Cs(I) ions and PB nanoparticles, then facilitate the adsorption. As shown in Fig. 3e and $\mathrm{f}$, the composite also exhibited strong mechanical strength, and the weight of the coin above the $\mathrm{PB} / \mathrm{rGOH}$ were 1788 and 3577 times of the dry-weight of itself, respectively. The photographs of the $\mathrm{PB} / \mathrm{rGOH}$ in Fig. $3 \mathrm{~g}$ and $\mathrm{h}$ show that after drying the $\mathrm{PB} / \mathrm{rGOH}$ shrunk to a stiff carbon bulk material, and the volume reduced to $1 / 125$ of its initial volume.

Fig. 4 shows the $\mathrm{N}_{2}$ adsorption/desorption isotherm and corresponding $\mathrm{BJH}$ pore-size distribution curve of the $\mathrm{PB} / \mathrm{rGOH}$. The isotherm revealed that the surface area of the composite was $98.21 \mathrm{~m}^{2} \mathrm{~g}^{-1}$, and the pore-sizes of the $\mathrm{PB} / \mathrm{rGOH}$ was ranged from 2 to $10 \mathrm{~nm}$ (Fig. 4 inset). The composite exhibited a pattern closely related to the Type IV adsorption isotherm, according to
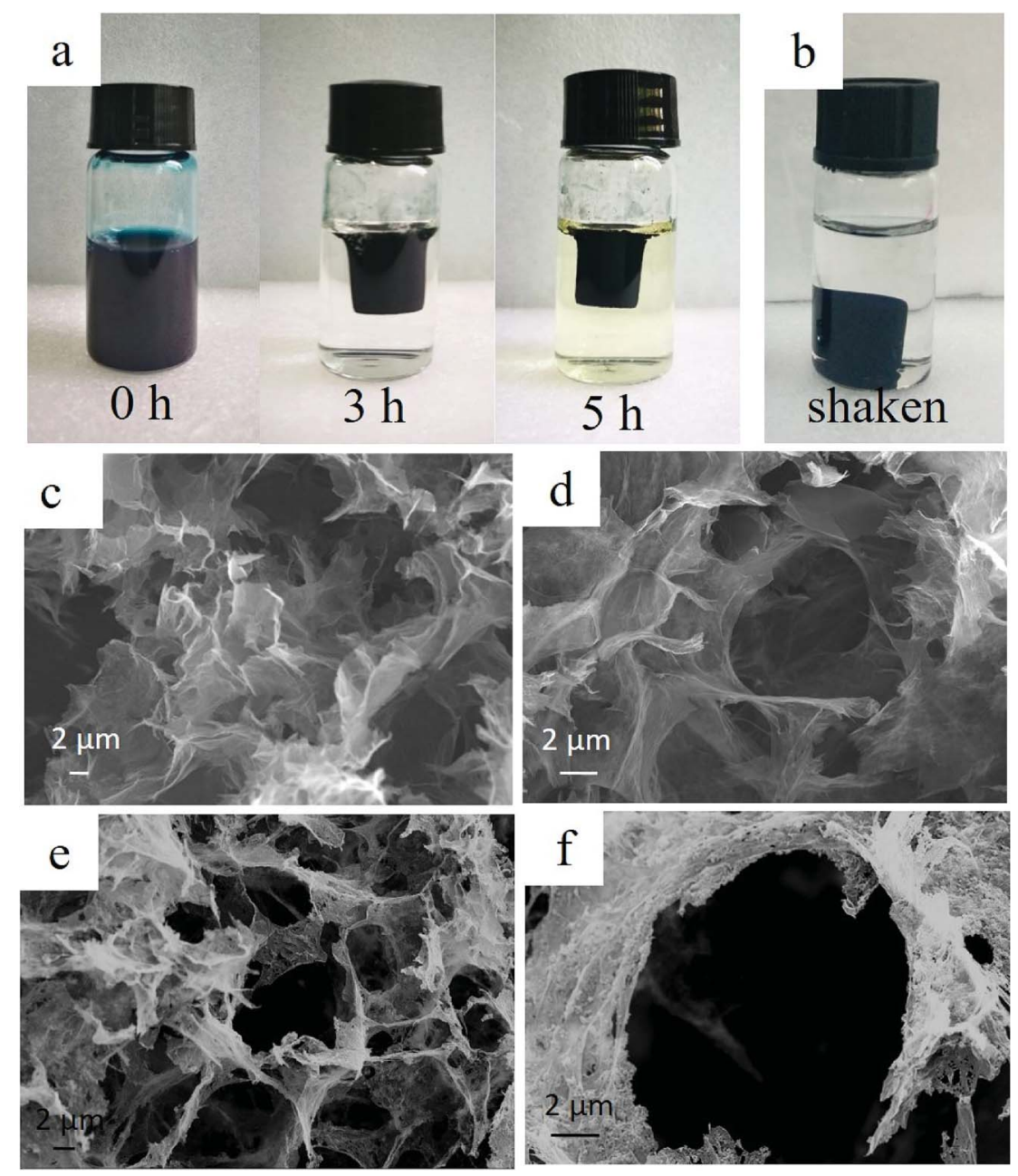

Fig. 2 (a) Images of the PB/rGOH at different reaction times; (b) image of the PB/rGOH after shaking for $72 \mathrm{~h}$; (c, d) SEM images of the freezedried $\mathrm{rGOH}$; and (e, f) SEM images of the freeze-dried PB/rGOH. 

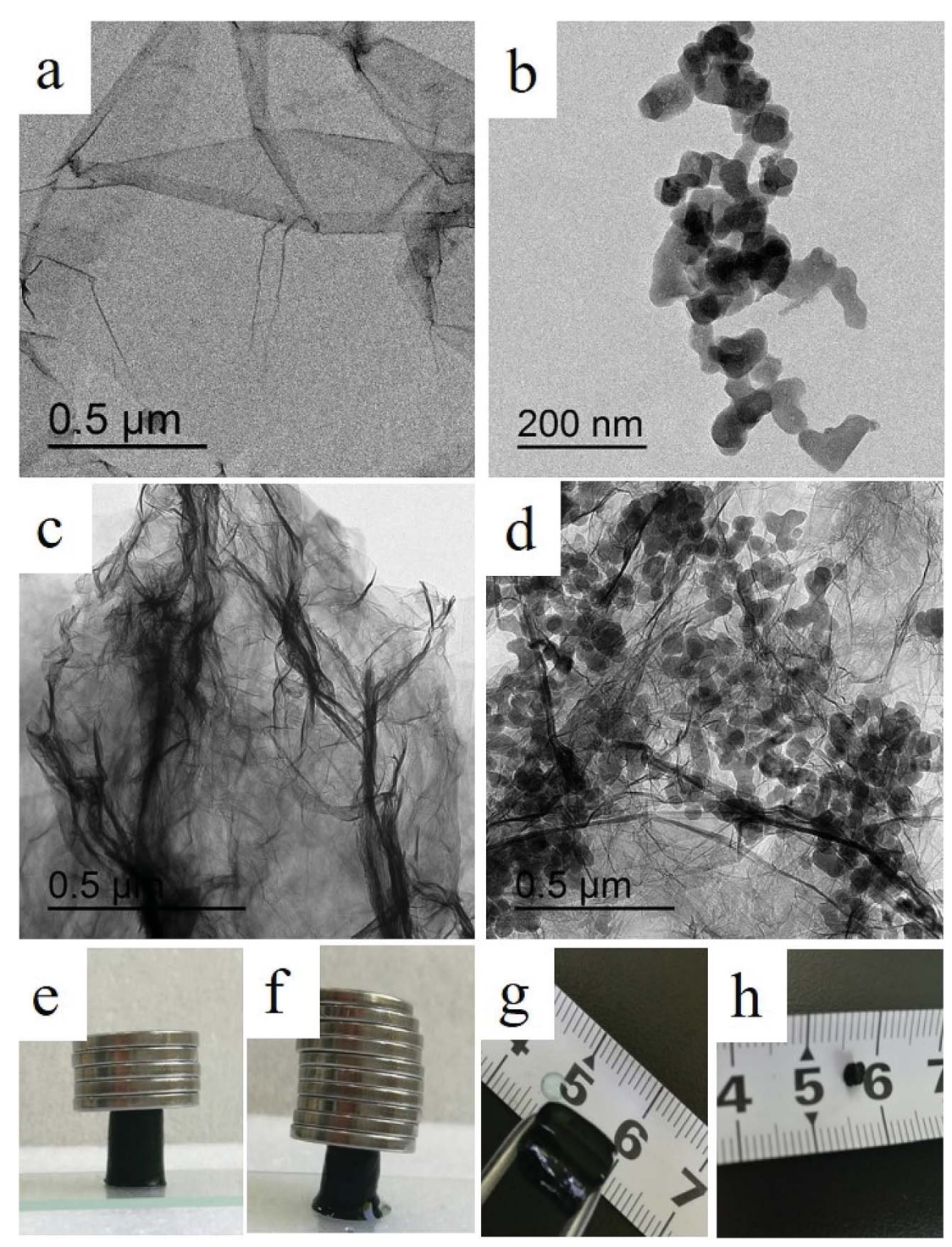

Fig. 3 TEM images of the GO (a), PB nanoparticles (b), rGO sheets (c), and PB/rGO sheets (d); (e and f) photographs of PB/rGOH allowing different supporting weight; ( $g$ and $h$ ) photographs of the $\mathrm{PB} / \mathrm{rGOH}$ before and after natural air drying.

the IUPAC classification, and showed steep $\mathrm{N}_{2}$ gas uptake at relatively low pressure region, indicating the mesoporous nature of the composite..$^{25}$

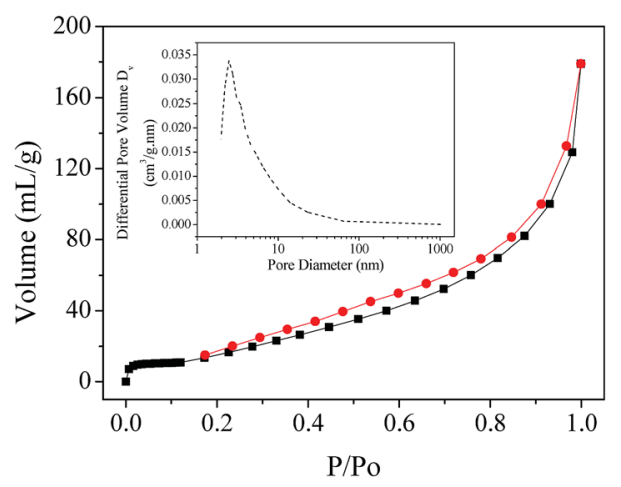

Fig. 4 Nitrogen adsorption/desorption isotherm of the $\mathrm{PB} / \mathrm{rGOH}$ (inset: the pore-size distribution).

\section{Chemical/physical properties}

XPS analysis provided detailed information on the chemical composition of the as-prepared materials. The sharp peaks in the full scan spectrum of $\mathrm{PB} / \mathrm{rGOH}$ revealed the presence of carbon, oxygen, nitrogen, and iron elements, and the relative oxygen content in $\mathrm{rGO}$ gel and $\mathrm{PB} / \mathrm{rGOH}$ were significantly lower than that of GO (Fig. 5a). To further understand the electronic states of the elements, higher-resolution spectra of $\mathrm{C} 1 \mathrm{~s}$ were also recorded (Fig. 5b-d). Four different peaks centered at 284.6, $285.5,287.0$, and $287.5 \mathrm{eV}$ were observed in the $\mathrm{C} 1 \mathrm{~s}$ deconvolution spectrum of $\mathrm{GO}$, corresponding to $\mathrm{C}=\mathrm{C} \mathrm{sp}{ }^{2}, \mathrm{C}-\mathrm{C} \mathrm{sp}$, $\mathrm{C}-\mathrm{O}$, and $\mathrm{C}=\mathrm{O}$, respectively (Fig. $5 \mathrm{~b}$ ). The spectrum of the rGOH (Fig. 5c) shows three peaks located at 284.4, 285.8, and $288.4 \mathrm{eV}$, respectively. The ratio of the oxygen containing groups decreased significantly, confirming the reduction of the GO. For the $\mathrm{PB} / \mathrm{rGOH}$, Fig. $5 \mathrm{~d}$ only shows $\mathrm{C} \equiv \mathrm{N}$ and matrix $\mathrm{C}-\mathrm{C}$ peaks at 285.5 and $284.5 \mathrm{eV}$, respectively. ${ }^{26}$ These results indicate that 

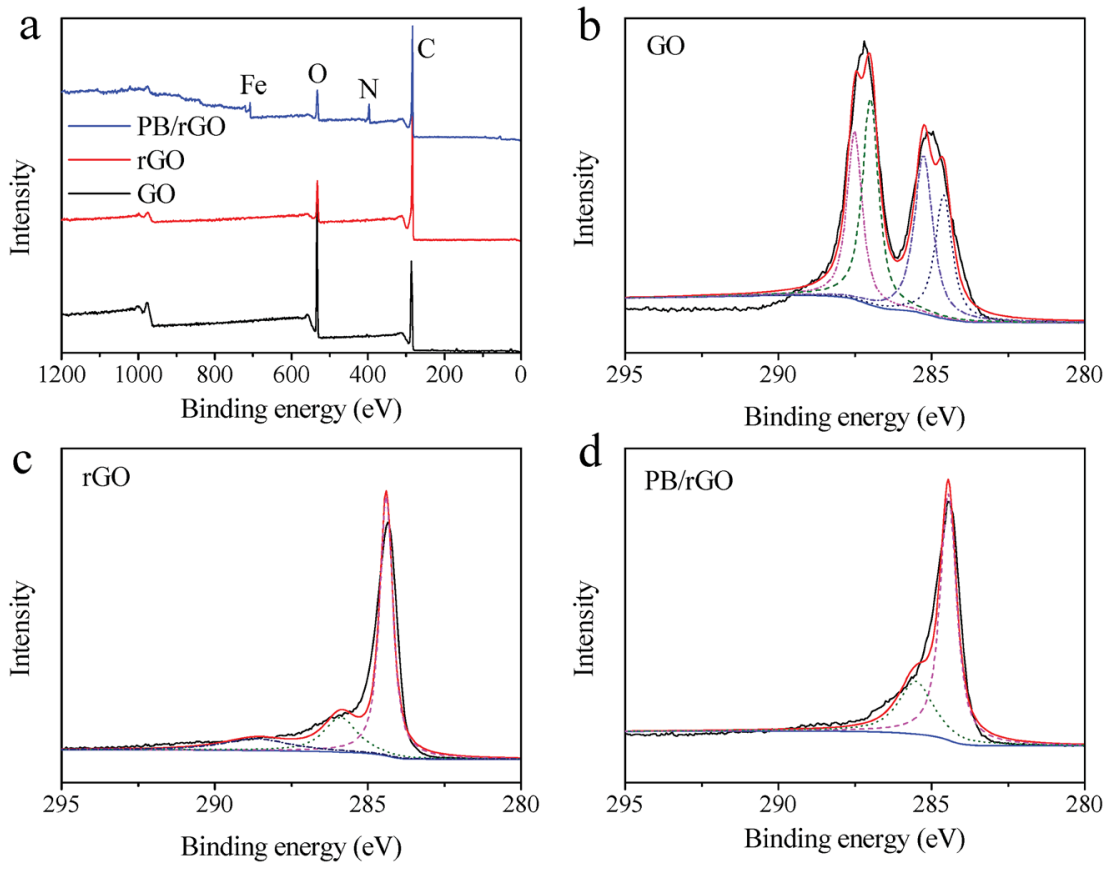

Fig. 5 Full scan XPS spectra of (a) GO, rGO, and PB/rGOH; (b) C 1s spectra of GO; (c) C 1s spectra of rGOH; and (d) C 1s spectra of PB/rGOH.

GO was effectively reduced to rGO, and PB nanoparticles were assembled in $\mathrm{rGOH}$ during the reduction process.

Fig. 6a shows the XRD patterns of $\mathrm{GO}, \mathrm{rGOH}, \mathrm{PB}$, and $\mathrm{PB} / \mathrm{rGOH}$. The characteristic $2 \theta$ peak for the $\mathrm{rGOH}$ appeared at $23.11^{\circ}$, corresponding to an interlayer spacing of $0.384 \mathrm{~nm}$. This value was much lower than that of GO $(0.881 \mathrm{~nm})$, suggesting the existence of $\pi-\pi$ stacking interaction between rGO sheets in the network, and further demonstrated the effective reduction of GO. The pattern of the $\mathrm{PB} / \mathrm{rGOH}$ shows almost the same characteristic peaks with $\mathrm{PB}$, which might be attributed to the low content of rGO in the material.

Raman spectra show the existence of D-band and G-band in $\mathrm{GO}, \mathrm{rGOH}$, and $\mathrm{PB} / \mathrm{rGOH}$ (Fig. 6b). The D-band is attributed to $\mathrm{A}_{1 \mathrm{~g}}$ photon of $\mathrm{sp}^{3}$ carbon atoms of disordered graphite, and the $\mathrm{G}$-band is related to the in-plane vibration of $\mathrm{sp}^{2}$ carbon atoms. The G-band of GO was located at $1593 \mathrm{~cm}^{-1}$, while that of $\mathrm{rGOH}$ was red shifted to $1588 \mathrm{~cm}^{-1}$, closing to the value of the pristine graphite, ${ }^{27}$ suggesting the elimination of oxygen containing groups and the enhancement of the gelation. However, the G-band of $\mathrm{PB} / \mathrm{rGOH}$ was blue shifted to $1592 \mathrm{~cm}^{-1}$, because the assembling of $\mathrm{PB}$ into the $\mathrm{rGOH}$ hindered the $\pi-\pi$ stacking interaction and inhibited the gelation of $\mathrm{rGOH}$.

GO contains many oxygen-containing functional groups on its surface, making it well dispersed in water. However, the reduction of GO could diminish the oxygenated groups on its surface and restore its conjugated domains, as evidenced by the XPS, XRD, and Raman spectra. Driven by the hydrophobic and $\pi-\pi$ stacking interaction of the conjugated structure, the crosslinking through partial overlapping of the rGO sheets occurs, and the volume gradually shrinks, accompanying with the embedding of PB nanoparticles inside. Finally, the sufficient cross-linking sites are generated for forming a 3D network. The
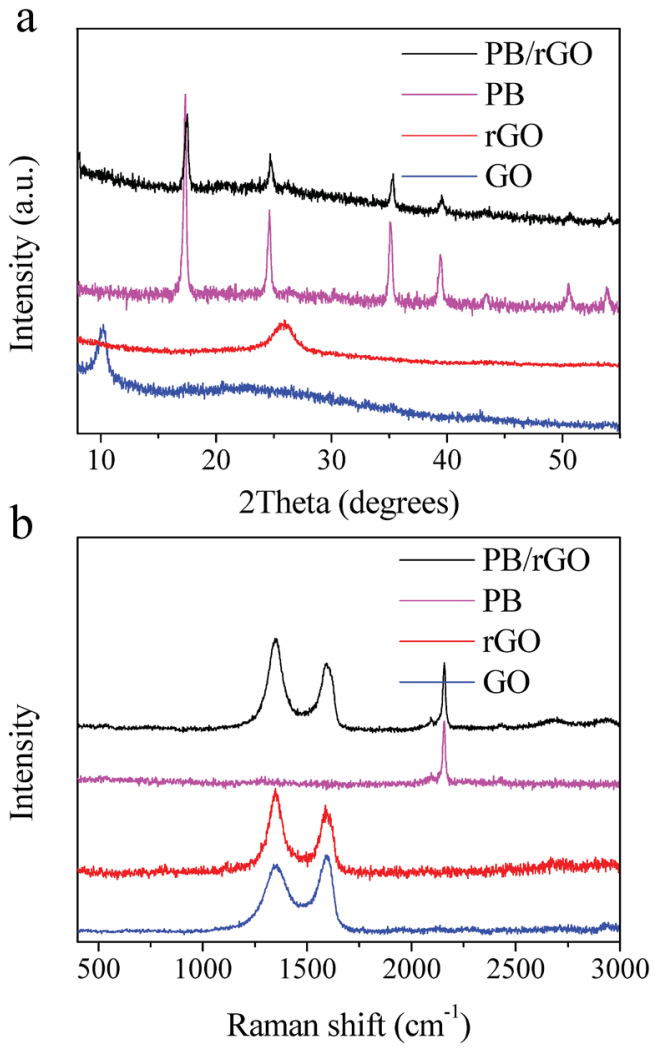

Fig. 6 XRD (a) and Raman spectra (b) of the GO, PB nanoparticles, $\mathrm{rGOH}$, and $\mathrm{PB} / \mathrm{rGOH}$.

PB nanoparticles can be captured by the rGOH in two approaches: firstly, when PB nanoparticles were mixed with GO suspension, some nanoparticles could be fixed on the surface of 


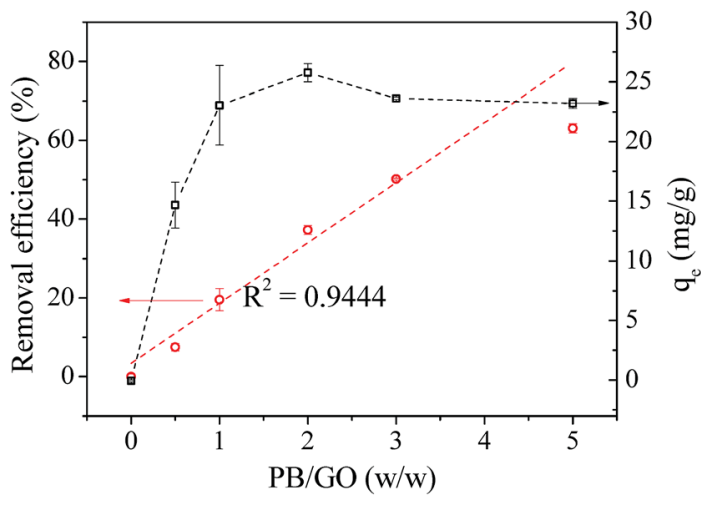

Fig. 7 The influence of the ratio of $\mathrm{PB} / \mathrm{GO}(\mathrm{w} / \mathrm{w})$ on the adsorption performance of the composites. $15 \mathrm{~mL}$ of $100 \mathrm{mg} \mathrm{L}^{-1} \mathrm{Cs}($ () was added into $20 \mathrm{~mL}$ glass bottle containing $\mathrm{PB} / \mathrm{rGOH}, \mathrm{pH}=5, T=25^{\circ} \mathrm{C}$, and the $\mathrm{Cs}(1)$ concentration of the supernatant was detected after $72 \mathrm{~h}$.

GO by forming new bonds between PB and GO due to the abundant oxygenated groups of $\mathrm{GO}$, and these nanoparticles were retained onto the surface of the rGO sheets by chemical attachment after GO was reduced. This process is similar to the reported method for preparing PB/RGO hybrids. ${ }^{28}$ Secondly, there are still more PB nanoparticles dispersed in the mixed suspension, which can be captured by the physical entrapment (between rGO sheets) during the formation of the 3D architecture. $^{29}$

The development of nuclear industry inevitably results in more and more production of radioactive wastewater. Radionuclide is a kind of specific pollutant, because its hazardness and toxicity cannot be changed by chemical and physical approaches. Isolation and its spontaneous decaying to stable nuclide is the only way to avoid irradiation hazard. Therefore, it is quite necessary to reduce the volume of the radioactive waste. After totally desiccated, the strong $\pi-\pi$ stacking interaction between the rGO sheets makes the $\mathrm{PB} / \mathrm{rGOH}$ further shrink to form graphite-like bulk materials, ${ }^{30}$ which is conducive for further reducing the volume of wastewater and will be beneficial to the waste minimization.

\section{Adsorption experiments}

The influence of $\mathrm{PB} / \mathrm{GO}(\mathrm{w} / \mathrm{w})$ ratio on the $\mathrm{Cs}(\mathrm{I})$ adsorption performance of $\mathrm{PB} / \mathrm{rGOH}$ was validated (Fig. 7). When the $\mathrm{PB} / \mathrm{GO}$ ratios were set $0,0.5,1,2,3,5$ in the preparation, the dried weights of the composites were $3 \mathrm{mg}, 6 \mathrm{mg}, 9 \mathrm{mg}, 16 \mathrm{mg}, 22 \mathrm{mg}$, and $30 \mathrm{mg}$, respectively. To conduct the $\operatorname{Cs}(\mathrm{I})$ adsorption experiments, the whole piece of hydrogel were put into the $\operatorname{Cs}(\mathrm{I})$ aqueous solution. As shown in Fig. 7, the RE continuous increased with the increase of the $\mathrm{PB} / \mathrm{GO}$ ratio. Meanwhile, in the absence of $\mathrm{PB}$, rGOH shows no adsorption of $\mathrm{Cs}(\mathrm{I})$, and the $\mathrm{Cs}(\mathrm{I})$ removal efficiency of the $\mathrm{PB} / \mathrm{rGOH}$ approximately follows a linear relationship with the ratio of $\mathrm{PB} / \mathrm{GO}$. This result indicates $\mathrm{PB}$ played the role of adsorbing $\mathrm{Cs}(\mathrm{I})$, while $\mathrm{rGOH}$ only acted as a support assembling for PB nanoparticles. The adsorption capacities of the composite increased along with the increase of $\mathrm{PB} / \mathrm{GO}$ ratio when it was lower than 2 and decreased slightly when the $\mathrm{PB} / \mathrm{GO}$ ratio was further increased. It is possible that when the ratio of $\mathrm{PB} / \mathrm{GO}$ is
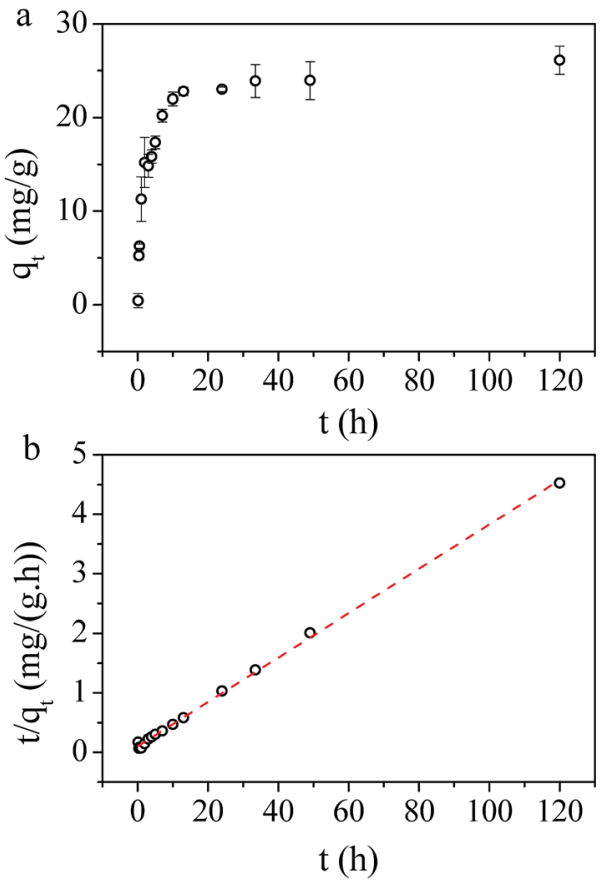

Fig. 8 (a) Influence of time on adsorption performance, and (b) adsorption kinetic plots of $t / q_{t} v s$. $t$. The dried weight of the $P B / r G O H$ was $9 \mathrm{mg}, \mathrm{Cs}(\mathrm{I})$ concentration was $40 \mathrm{mg} \mathrm{L}^{-1}(15 \mathrm{~mL}), \mathrm{pH}=4, T=$ $25^{\circ} \mathrm{C}$.

low, the weight of the rGO accounts a large share of the composite, which decreases the adsorption capacity of PB nanoparticles itself. However, as the $\mathrm{PB} / \mathrm{GO}$ ratio further increased, the weight proportion of the rGO become smaller, so the adsorption capacity of the composite got closer to that of the PB nanoparticles. Meanwhile, it was found that $\mathrm{PB} / \mathrm{rGOH}$ were stable after $72 \mathrm{~h}$ of shaking when the ratio of $\mathrm{PB} / \mathrm{GO}$ was lower than 2, while the ratio of $\mathrm{PB} / \mathrm{GO}$ is higher than 2, there would be some $\mathrm{PB}$ nanoparticles released by the $\mathrm{rGOH}$. So, from a stability point of view, the $\mathrm{PB} / \mathrm{GO}$ ratio of 1 was used in the followed experiments.

The effect of contact time on the $\mathrm{Cs}(\mathrm{I})$ adsorption of $\mathrm{PB} / \mathrm{rGOH}$ is presented in Fig. 8a. A rapid uptake of $\mathrm{Cs}(\mathrm{I})$ ions was observed after addition of $\mathrm{PB} / \mathrm{rGOH}$, and about $50 \%$ of the equilibrium adsorption capacity was reached within the first 2 hours, while 10 hours were sufficient to achieve $85 \%$ of the equilibrium adsorption capacity. The equilibrium time for $\mathrm{Cs}(\mathrm{I})$ adsorption needed by $\mathrm{PB} / \mathrm{rGOH}$ was longer than that by $\mathrm{PB}$ nanoparticles, which was due to the limited mass transfer rate in the hydrogel. ${ }^{31}$ However, this value was comparable with those studies in which PB nanoparticles were embedded into chitin beads, alginate/calcium beads, etc. . $^{32,33}$

In order to understand the dynamics of the adsorption process, kinetic data were analyzed using pseudo-first-order and

Table 1 Rate constants and correlation coefficients of the pseudosecond-order kinetic model

\begin{tabular}{lllll}
\hline & $q_{\mathrm{e}}\left(\mathrm{mg} \mathrm{g}^{-1}\right)$ & $k_{2}\left(\mathrm{~g}(\mathrm{mg} \mathrm{h})^{-1}\right)$ & $V_{0}\left(\mathrm{mg}(\mathrm{g} \mathrm{h})^{-1}\right)$ & $R^{2}$ \\
\hline $\mathrm{PB} / \mathrm{rGOH}$ & 26.83 & 0.0135 & 9.74 & 0.99
\end{tabular}



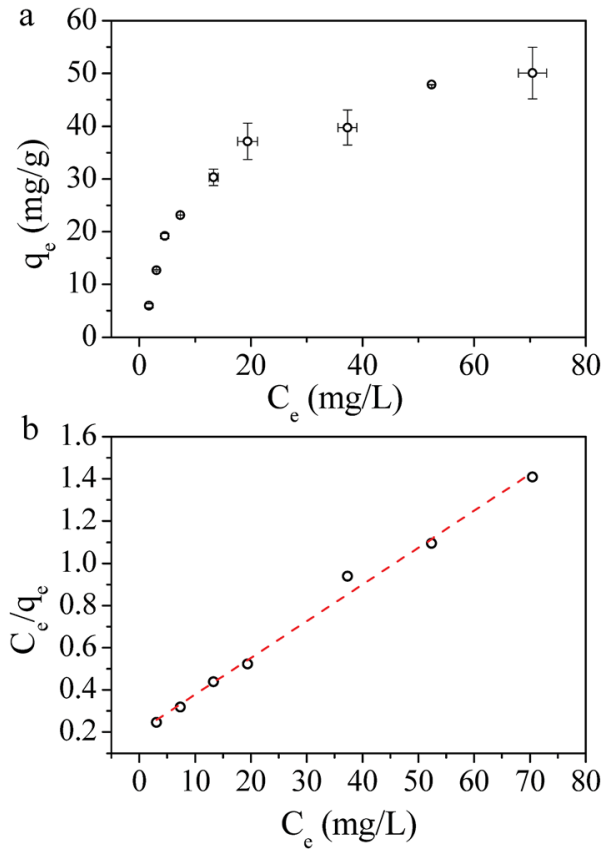

Fig. 9 (a) Influence of concentration on adsorption performance, and (b) Langmuir isotherms. The dried weight of the PB/rGOH was $9 \mathrm{mg}$, the volume of $\mathrm{Cs}(\mathrm{I})$ were $15 \mathrm{~mL}$, and $\mathrm{pH}=5, T=25^{\circ} \mathrm{C}, t=72 \mathrm{~h}$.

pseudo-second-order kinetics. The results in our work perfectly follows pseudo-second-order kinetic model, which is expressed as:

$$
\frac{t}{q_{t}}=\frac{1}{k_{2} q_{\mathrm{e}}^{2}}+\frac{t}{q_{\mathrm{e}}}
$$

where $q_{t}$ is the amount of adsorbed pollutant on per unit weight of adsorbent $\left(\mathrm{mg} \mathrm{g}^{-1}\right)$ at time $t(\mathrm{~h}), q_{\mathrm{e}}$ is the sorption capacity at equilibrium $\left(\mathrm{mg} \mathrm{g}^{-1}\right)$, and the parameter $k_{2}\left(\mathrm{~g}(\mathrm{mg} \mathrm{h})^{-1}\right)$ represents the pseudo-second-order rate constant for the kinetic model. The fitting of the experimental data to the pseudo-secondorder model $\left(R^{2}=0.995\right)$ suggested that $\mathrm{Cs}(\mathrm{I})$ adsorption on $\mathrm{PB} / \mathrm{rGOH}$ is a chemisorption rather than a physisorption (Table 1 and Fig. $8 \mathrm{~b}) \cdot{ }^{34}$ Calculated from the fitting results, the values of $q_{\mathrm{e}}$ and $k_{2}$ were obtained as $26.83 \mathrm{mg} \mathrm{g}^{-1}$ and $0.0135 \mathrm{~g}(\mathrm{mg} \mathrm{h})^{-1}$, respectively. From these values, the initial adsorption rate of $9.74 \mathrm{~g}(\mathrm{mg} \mathrm{h})^{-1}$ was calculated using the equation $V_{0}=k_{2} q_{\mathrm{e}}{ }^{2} \cdot{ }^{35}$

Adsorption isotherm can provide information about adsorption mechanisms, surface properties, and the affinity of the adsorbent towards the adsorbate. In this study, the adsorption of $\mathrm{Cs}(\mathrm{I})$ ions with different initial concentrations were studied at $298 \mathrm{~K}$ and $\mathrm{pH}=5$, with an adsorption time $t=$ $72 \mathrm{~h}$ (Fig. 9a). To explore the adsorption mechanism, we validated the relationship between adsorbed cesium and its residual in aqueous solution at adsorption equilibrium

Table 2 Langmuir isotherm constants and their correlation coefficients

\begin{tabular}{llll}
\hline & $Q_{\max }\left(\mathrm{mg} \mathrm{g}^{-1}\right)$ & $b\left(\mathrm{~L} \mathrm{mg}^{-1}\right)$ & $R^{2}$ \\
\hline $\mathrm{PB} / \mathrm{rGOH}$ & 58.82 & 0.0837 & 0.99
\end{tabular}

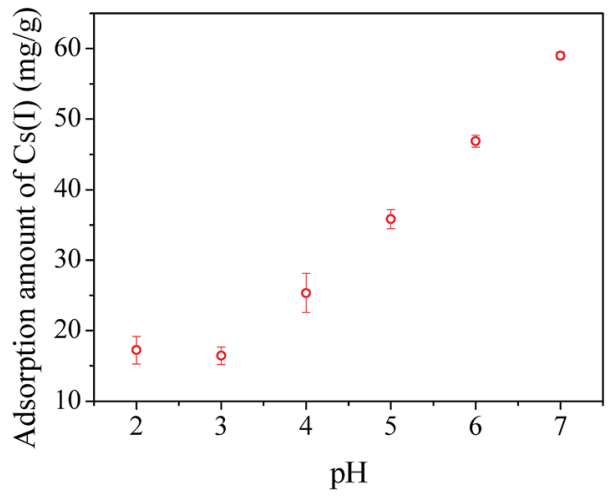

Fig. 10 Influence of $\mathrm{pH}$ on adsorption capacity. The dried weight of $\mathrm{PB} / \mathrm{rGOH}$ was $9 \mathrm{mg}$, Cs(I) concentration was $40 \mathrm{mg} \mathrm{L}^{-1}(15 \mathrm{~mL}), T=$ $25^{\circ} \mathrm{C}, t=72 \mathrm{~h}$.

according to the Langmuir model and Freundlich model. The experimental adsorption data fitted well with Langmuir isotherms (Fig. 9b), suggesting that the adsorbent surface was heterogeneous in nature. The linear form of the Langmuir isotherm is represented by:

$$
\frac{C_{\mathrm{e}}}{q_{\mathrm{e}}}=\frac{1}{Q_{\max } b}+\frac{C_{\mathrm{e}}}{Q_{\max }}
$$

where $C_{\mathrm{e}}\left(\mathrm{mg} \mathrm{L}^{-1}\right)$ is the equilibrium concentration of $\mathrm{Cs}(\mathrm{I}), q_{\mathrm{e}}$ $\left(\mathrm{mg} \mathrm{g}^{-1}\right)$ is the equilibrium sorption capacity of the adsorbent, $b$ is the Langmuir constants relating to the energy of adsorption $\left(\mathrm{L} \mathrm{mg}^{-1}\right)$, and $Q_{\max }$ is the maximum adsorption capacity $\left(\mathrm{mg} \mathrm{g}^{-1}\right)$. The Langmuir isotherm constants and their correlation coefficients for $\mathrm{PB} / \mathrm{rGOH}$ are listed in Table 2 . The $Q_{\max }$ value for $\mathrm{PB} / \mathrm{rGOH}$ is $58.82 \mathrm{mg} \mathrm{g}^{-1}$, which is comparable with many PB-based adsorbents reported previously. ${ }^{26,36}$ However, this value is lower than the value of $\mathrm{PB}$ functionalized $\mathrm{Fe}_{3} \mathrm{O}_{4}\left(280.82 \mathrm{mg} \mathrm{g}^{-1}\right),{ }^{13}$ but higher than that of $\mathrm{PB} / \mathrm{RGOF}$ reported by Jang et al. $\left(18.67 \mathrm{mg} \mathrm{g}^{-1}\right) .{ }^{25}$ This could be mainly attributed to the difference of the size of the nanoparticles and the surface area of the composites. ${ }^{13,37}$ The surface area of $\mathrm{PB} / \mathrm{rGOH}$ in our work was $98.21 \mathrm{~m}^{2} \mathrm{~g}^{-1}$, and the size of the PB was 50-100 nm; while the $\mathrm{PB} / \mathrm{Fe}_{3} \mathrm{O}_{4}$ mentioned above had surface area of $332.19 \mathrm{~m}^{2} \mathrm{~g}^{-1}$ and size of $13.9 \mathrm{~nm}$, and the PB/RGOF in ref. 25 showed a surface area of $43.07 \mathrm{~m}^{2} \mathrm{~g}^{-1}$.

$\mathrm{pH}$ value is one of the most important parameters affecting the adsorption capacity. In this study, experiments were conducted at different $\mathrm{pH}$ values from 2 to 7. As shown in Fig. 10, the $\mathrm{Cs}(\mathrm{I})$ adsorption capacity of $\mathrm{PB} / \mathrm{rGOH}$ gradually increased with elevated $\mathrm{pH}$ values from 3.0 to 7.0 , which could be attributed to that the adsorption of Cs(I) was suppressed due to the competition of $\mathrm{H}_{3} \mathrm{O}^{+}{ }^{26,38}$ Further increasing the $\mathrm{pH}$ value resulted in serious decomposition of $\mathrm{PB}$ nanoparticles in our study, which interfere the measurement. The low stability of the PB was due to the strong interaction between ferric ions and hydroxyl ions at alkaline condition, which resulted in $\mathrm{Fe}-\mathrm{CN}-\mathrm{Fe}$ bond cleavage in $\mathrm{PB} .{ }^{39,40}$

\section{Conclusions}

In the present work, we have successfully developed $\mathrm{PB} / \mathrm{rGOH}$ for $\mathrm{Cs}(\mathrm{I})$ removal. The as-prepared materials displayed a $3 \mathrm{D}$ 
porous network, and the PB nanoparticles distributed uniformly on the rGO sheets. The materials could be separated easily from aqueous solution. Moreover, the volume of the hydrogel could shrink to one in 125 of its initial volume after natural air dry, which will be beneficial for the waste minimization. It was demonstrated that in the $\mathrm{PB} / \mathrm{rGOH}$, the $\mathrm{Cs}(\mathrm{I})$ adsorption was dominated by PB nanoparticles, and the $\mathrm{rGOH}$ played the role of supporting substrate and making it easy to separate from water. The Cs(I) adsorption performance of the $\mathrm{PB} / \mathrm{rGOH}$ fitted well with the pseudo-second-order kinetic and the Langmuir isotherm model, and an maximum adsorption capacity of $58.82 \mathrm{mg} \mathrm{g}^{-1}$ was obtained. In addition, we also found that $\mathrm{Cs}(\mathrm{I})$ adsorption significantly depends on the $\mathrm{pH}$ of solution. These results demonstrated that the $\mathrm{PB} / \mathrm{rGOH}$ have a good application prospect in radioactive waste water treatment.

\section{Conflicts of interest}

There are no conflicts to declare.

\section{Acknowledgements}

The authors of this paper would like to thank National Science Foundation of China (Grant No. 21707127), National Science Foundation of China (Grant No. 21607141), Innovation Foundation of Institute of Nuclear Physics and Chemistry (Grant No. 2015CX01), and The Science Challenge Project (JCKY2016212A504) for financial support.

\section{References}

1 http://www.iea.org/publication/freepublications/ publication/keyworld2016.pdf.

2 M. J. Manos and M. G. Kanatzidis, J. Am. Chem. Soc., 2012, 134, 16441-16446.

3 J. Johnson, Chem. Eng. News, 1998, 76, 25-27.

4 S. Merz, K. Shozugawa and G. Steinhauser, Environ. Sci. Technol., 2015, 49, 2875-2885.

5 M. R. Awual, S. Suzuki, T. Taguchi, H. Shiwaku, Y. Okamoto and T. Yaita, Chem. Eng. J., 2014, 242, 127-135.

6 S. Y. Ding, Y. Yang, H. O. Huang, H. C. Liu and L. A. Hou, J. Hazard. Mater., 2015, 294, 27-34.

7 C. Vincent, Y. Barre, T. Vincent, J. M. Taulemesse, M. Robitzer and E. Guibal, J. Hazard. Mater., 2015, 287, 171-179.

8 L. Chang, S. Chang, W. Chen, W. Han, Z. Li, Z. Zhang, Y. Dai and D. Chen, RSC Adv., 2016, 6, 96223-96228.

9 D. R. Melo, J. L. Lipsztein, C. A. N. Oliveira and L. Bertelli, Radiation Protection/Medical Aspects of the Goiania Accident, Individual Monitoring, REMPAN 97, 1997, pp. 185-188.

10 S. Feng, X. Li, F. Ma, R. Liu, G. Fu, S. Xing and X. Yue, RSC $A d v .$, 2016, 6, 34399-34410.

11 M. Darder, RSC Adv., 2014, 4, 35415-35421.

12 J. Qian, J. Ma, W. He and D. D. Hua, Chem.-Asian J., 2015, 10, 1738-1744.
13 J. Jang and D. S. Lee, Ind. Eng. Chem. Res., 2016, 55, 38523860.

14 A. K. Vipin, B. Fugetsu, I. Sakata, A. Isogai, M. Endo, M. Li and M. S. Dresselhaus, Sci. Rep., 2016, 6, 37009-37022.

15 H. Yang, L. Sun, J. Zhai, H. Li, Y. Zhao and H. Yu, J. Mater. Chem. A, 2013, 2, 326-332.

16 Y. Huang, M. Zeng, Z. Feng, D. Yin, Q. Xu and L. Fan, RSC Adv., 2016, 6, 3561-3570.

17 A. Pourjavadi, M. Nazari, B. Kabiri, S. H. Hosseini and C. Bennett, RSC Adv., 2016, 6, 10430-10437.

18 C. Du, Z. Yao, Y. Chen, H. Bai and L. Li, RSC Adv., 2014, 4, 9133-9138.

19 M. Gao, C. K. N. Peh, L. O. Wei and G. W. Ho, RSC Adv., 2013, 3, 13169-13177.

20 W. Li, Y. Ye, X. Lu, W. Yi, L. Sun, H. Tan, F. Xu and Y. Song, Electrochim. Acta, 2013, 114, 223-232.

21 H. Q. Gong, M. H. Sun, R. H. Fan and L. Qian, Microchim. Acta, 2013, 180, 295-301.

22 B. Adhikari, A. Biswas and A. Banerjee, ACS Appl. Mater. Interfaces, 2012, 4, 5472-5482.

23 Z. Zhang, T. Sun, C. Chen, F. Xiao, Z. Gong and S. Wang, ACS Appl. Mater. Interfaces, 2014, 6, 21035-21040.

24 Y. Xu, H. Bai, G. Lu, C. Li and G. Shi, J. Am. Chem. Soc., 2008, 130, 5856-5857.

25 S. C. Jang, Y. Haldorai, G. W. Lee, S. K. Hwang, Y. K. Han, C. Roh and Y. S. Huh, Sci. Rep., 2015, 5, 17510-17519.

26 H. J. Yang, L. Sun, J. L. Zhai, H. Y. Li, Y. Zhao and H. W. Yu, J. Mater. Chem. A, 2014, 2, 326-332.

27 W. Chen and L. Yan, Nanoscale, 2011, 3, 3132-3137.

28 N. Zhu, S. Han, S. Gan, J. Ulstrup and Q. Chi, Adv. Funct. Mater., 2013, 23, 5297-5306.

29 W. F. Chen, S. R. Li, C. H. Chen and L. F. Yan, Adv. Mater., 2011, 23, 5679-5683.

30 Y. Xu, Z. Lin, X. Huang, Y. Wang, Y. Huang and X. Duan, Adv. Mater., 2013, 25, 5779-5784.

31 M. Ishizaki, S. Akiba, A. Ohtani, Y. Hoshi, K. Ono, M. Matsuba, T. Togashi, K. Kananizuka, M. Sakamoto and A. Takahashi, Dalton Trans., 2013, 42, 16049-16055.

32 A. K. Vipin, B. Hu and B. Fugetsu, J. Hazard. Mater., 2013, 258-259, 93-101.

33 T. Vincent, C. Vincent, Y. Barré, Y. Guari, G. L. Saout and E. Guibal, J. Mater. Chem. A, 2014, 2, 10007-10021.

34 A. A. Kadam, J. Jang and D. S. Lee, Bioresour. Technol., 2016, 216, 391-398.

35 H. Faghihian, M. Moayed, A. Firooz and M. Iravani, J. Colloid Interface Sci., 2013, 393, 445-451.

36 H. Yang, H. Li, J. Zhai, L. Sun, Y. Zhao and H. Yu, Chem. Eng. J., 2014, 246, 10-19.

37 D. Parajuli, A. Kitajima, A. Takahashi, H. Tanaka, H. Ogawa, Y. Hakuta, K. Yoshino, T. Funahashi, M. Yamaguchi and M. Osada, J. Environ. Radioact., 2016, 151, 233-237.

38 T. Sangvanich, V. Sukwarotwat, R. J. Wiacek, R. M. Grudzien, G. E. Fryxell, R. S. Addleman, C. Timchalk and W. Yantasee, J. Hazard. Mater., 2010, 182, 225-231.

39 F. Ricci, A. Amine, G. Palleschi and D. Moscone, Biosens. Bioelectron., 2003, 18, 165-174.

40 J. Jang and D. S. Lee, Bioresour. Technol., 2016, 218, 294-300. 